\title{
Design of a Stator for a High-Speed Turbo-generator with Fixed Permanent Magnet Rotor Radius and Volt-Ampere Constraints
}

\author{
Nuwantha Fernando, Member, IEEE, Puvan Arumugam, Member, IEEE and Chris Gerada, Member, IEEE
}

\begin{abstract}
This paper investigates high-speed surface PM machine design for portable turbo-generator applications. The rotor radius is fixed to achieve certain optimal characteristics of the magnet retention mechanism. The basis of this paper is to design and select the stator. The stator designs are populated by different slot/pole combinations, winding arrangements and over a range of possible stack lengths. However, the design is constrained by physical diameter, stack length and electrical volt-ampere constraints. A large number of preliminary machine designs do not satisfy the specified turbo-generator torque/speed requirements under the given volt-ampere constraints and therefore it is ineffective to perform Finite Element analysis on all preliminary design variations. In order to establish the feasibility of a machine design to fulfill the specified turbo-generator torque/speed requirements, the concept of inductance-limits is presented and then linked with stator design parameters. By application of this analysis strategy, a confined optimal set of stator designs are obtained and are subjected to detailed finite element simulations. A final machine design is selected and fabricated. Experimental results are presented for the validation of the final machine design.
\end{abstract}

Index Terms-permanent magnet machine, field-weakening, high-speed machines, leakage inductance model

\section{INTRODUCTION}

$\mathbf{R}$ ECENT trends in the transportation sector have moved towards portable turbo-electric systems [1] particularly for more-electric [2] and hybrid-electric aircraft applications. These systems have limited voltage, e.g. $270 \mathrm{~V}$ DC specified in MIL-STD-704F standards [3]. The design of a portable turbo-generator is also delimited by low weight and low voltampere requirements. Placement of the turbo-generator impose physical constraints and therefore leads to a challenging design problem.

Due to high speeds, the magnets require specially designed retention, e.g. sleeve in addition to bonding [4]. It is shown in [4], [5] that the rotor radius can be fixed at an optimal value in order to maintain these stresses at safe levels while

Manuscript received $\mathrm{xxxx} \mathrm{xx}, 2017$; revised $\mathrm{xxxx} \mathrm{xx}, 2017$ and $\mathrm{xxxx} \mathrm{xx}$, 2016; accepted xxxx xx, 2018. This work was funded under the 7th FWP (Seventh Framework Programme) Joint Technology Initiatives - theme Clean Sky. Project Code: JTI-CS-2011-1-ECO-02-009 Alternator with active power rectification and health monitoring

The corresponding author is Nuwantha Fernando and is currently with the RMIT University, Melbourne Australia. (email: nfdo@ieee.org)

Puvan Arumugam is currently with Romax Technologies Ltd, Nottingham Ltd, UK

Chris Gerada is with the Power Electronics, Machines and Control Group, Faculty of Engineering, The University of Nottingham, University Park, Nottingham NG7 2RD, U.K. also achieving the maximum rotor air-gap flux density. The purpose of this paper is to develop a strategy to design the stator of a high-speed permanent magnet (PM) machine within given specifications when the rotor radius is fixed. The paper develops a strategy that links volt-ampere limitations to stator design parameters such as stack-length, slot/pole combination and winding arrangement. This allows the possibility to rapidly evaluate multiple stator designs with a reduced number of Finite Element (FE) simulations. A large number of machine designs can be eliminated due to their inability to satisfy the specified turbo-generator torque/speed requirements within the volt-ampere boundary [6].

The operation of PM machines with volt-ampere limitations is a well-documented problem [7]. Majority of the past research and popular literature [8], [9] deal with control of PM machines to achieve expanded operating torque/speed range. Conversely, the operational capability under given voltampere constraints has been studied by the authors of [10] The implications of machine saliency ratio and the magnet thickness have also been studied by the authors of [11] and [12]. The established analysis techniques can be utilized to calculate the required inductance and PM flux linkage to achieve a specific torque/speed operating point of a PM machine design. However, a technique to rapidly establish the capability of a machine design described by physical design parameters, torque/speed requirements and volt-ampere limits is not widely available. Availability of this form of evaluation technique using analytical means will be extremely useful for electrical machine designers. The primary objective of this paper is to develop such a technique and is undertaken by extension of existing concepts and introduction of the concept of inductance-limits analysis. The inductance limits are evaluated to ascertain the feasibility of multiple machine designs over a range of stack-length, slot/pole combinations, winding design and number of winding turns. A selected set of feasible designs are then further evaluated. This process eliminates a large cohort of infeasible designs early on in the process thus reducing the need for extensive FE analysis on these designs.

The inductance and PM flux linkage significantly influence the PM machine capability to fulfill a specific turbo-generator torque/speed profile. Therefore it is essential that an accurate estimation of these parameters be made at each instant the physical dimensions of a machine are adjusted in the design process. Pure analytical calculations alone do not yield the 
required accuracy [13] and therefore FE analysis is required. This is particularly important if a high proportion of inductance is contributed by the end winding portion, mainly due to low stack-length to outer diameter ratio [14]. In order to determine the influence of end-windings, 3D simulations are required and are not efficient to perform extensive $3 \mathrm{D} \mathrm{FE}$ analyses on machine designs that eventually may not fulfill the specific turbo-generator torque/speed profile. The secondary objective of this paper is to combine the existing analytical modelling techniques with a low number of FE simulations to determine a scalable set of electrical parameters which can be used to effectively calculate variations of inductance and PM flux linkage with the adjustment of number of winding turns and stack-length.

Sec. II outlines the selection of the preliminary stator dimensions. Sec. III presents the relationship between inductance, PM flux linkage and the physical dimensions. Sec. IV outlines the development of the inductance vs. speed analysis technique to determine the feasibility of a given machine design. The application of this design strategy for a prototype turbo-generator design is described in Sec. V. Simulation and experimental results are discussed in Sec. VI. Sec. VII concludes the paper.

\section{SELECTION OF PRELIMINARY STATOR DIMENSIONS}

\section{A. The fixed rotor radius}

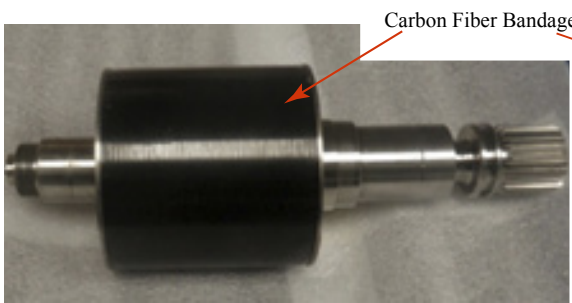

(a)

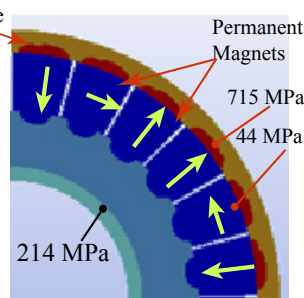

(b)
Fig. 1. Fixed rotor radius: (a) fabricated prototype and (b) the cross section of a 6-pole rotor with mechanical stress distribution plot

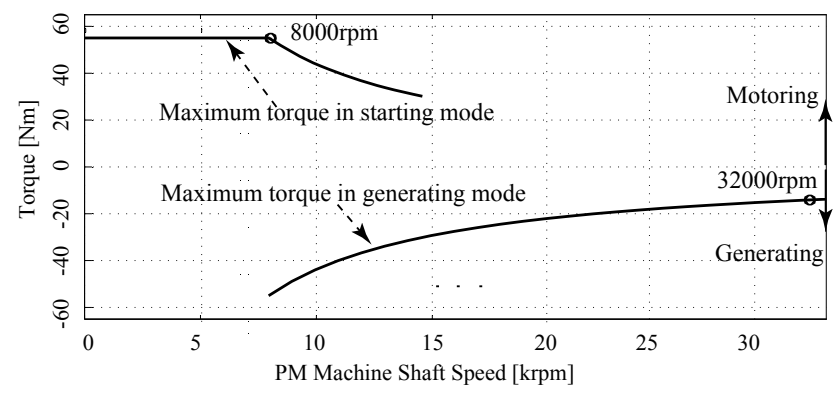

Fig. 2. Torque speed requirements of the turbo-generator

In this research, the design of the stator is considered around a fixed rotor radius shown in Fig. 1 (a) and (b). The torque/speed requirements for the turbo-generator is shown in Fig. 2 and also operates as a starter motor in the low-speed region. Due to high-speed operation, the magnet retention is with the use of a Carbon Fiber bandage. The rotor design
TABLE I

TERMINOLOGY AND SYMBOLS OF KEY DESIGN PARAMETERS

\begin{tabular}{ll||ll}
\hline \hline Quantity & Symbol & Quantity & Symbol \\
\hline Number of slots & $Q$ & No of winding layers & $N_{l y}$ \\
No of poles & $p$ & No of conductors & $N_{c}$ \\
No of phases & $m$ & per-slot per-layer & \\
Slot per-pole per-phase & $q$ & No of series & $N_{s}$ \\
Stack length & $l_{s t k}$ & Turns per-phase & \\
Stator inner diameter & $D_{i s}$ & Stator tooth width & $w_{s p}$ \\
Air-gap thickness & $g$ & Stator tooth depth & $h_{s 2}$ \\
Coil pitch & $\tau_{c}$ & Stator back-iron & $h_{s 3}$ \\
Fundamental & $k_{w, 1}$ & thickness & Stator tooth edge \\
winding factor & $h_{p m}$ & dimensions & $b_{s 0}, h_{s 0}$ \\
Magnet thickness & \multicolumn{2}{|}{} \\
\hline
\end{tabular}

has been presented in [5] and is shown that when the rotor diameter is increased, the bandage thickness also has to be increased to lower the mechanical stresses [5], [15]. This results in lower air-gap flux density and leads to a heavier machine. As a result, an optimal rotor diameter, bandage thickness and magnet thickness are determined with consideration of mechanical strength and volume and therefore is considered as fixed specifications for the stator design. The rotor magnets are placed in Halbach arrangement as shown in Fig. 1 (b). The number of rotor poles does not impact the stresses in the carbon fiber bandage. Therefore, the rotor pole number is considered as a variable that can be adjusted in the stator design process.

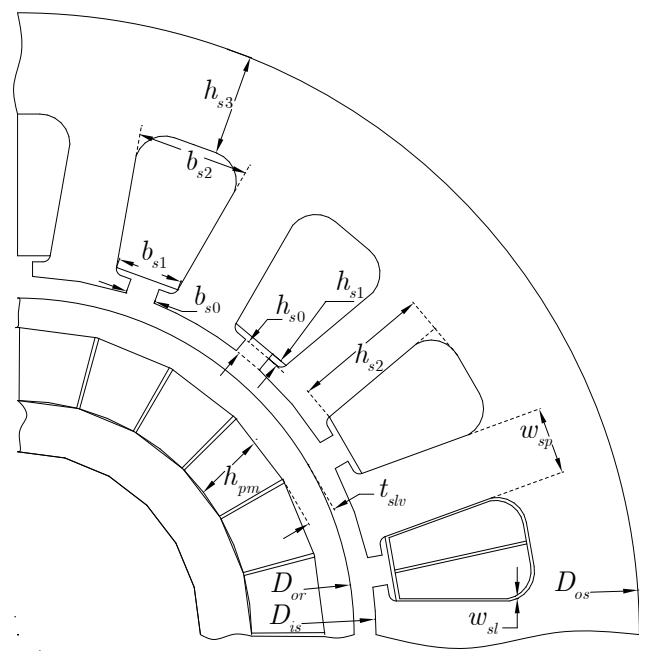

Fig. 3. Cross section of a PM machine and corresponding dimensions

\section{B. winding arrangement}

Given a fixed rotor radius, the stator geometry and winding design involve the selection of the parameters given in Table I. Fig. 3 shows the corresponding dimensions in a quarter crosssection of an example 6-pole/ 18-slot stator.

Both a single layer winding topology and a double layer winding topology are considered. While the rotor radius and magnet thickness are fixed, stack length and winding design parameters are variables, and the number of rotor poles is varied from 4, 6 and 8. Rotor pole numbers above eight 


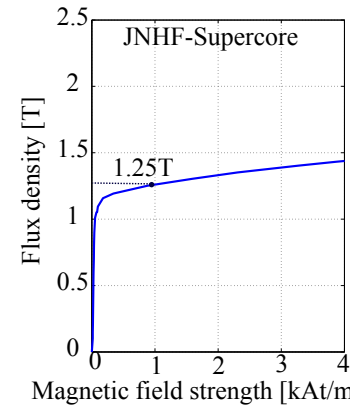

(a)

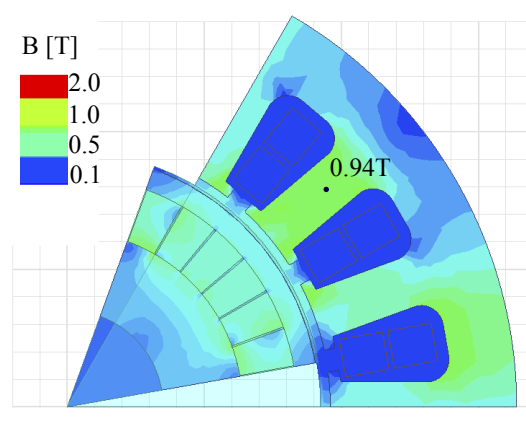

(b)
Fig. 4. (a) B-H curves of the candidate material $6.5 \% \mathrm{Si}-\mathrm{Steel}$ and (b) example flux density plot of the stator of a $6 / 18$ machine

are not considered, as it leads to high electrical frequencies and higher power converter losses. Due to the high-speed operational requirements, the MMF harmonics induces eddy currents within the magnets [16], [17] leading to high rotor temperatures. In order to mitigate this effect, the winding topology for each slot/pole combination and winding parameters are selected such that the winding harmonics are minimized for an acceptable trade-off the fundamental winding factor.

\section{Basis for the selection of the stator tooth width:}

Fig. 4 (a) presents the B-H curves of the candidate core material, namely $6.5 \%$ Silicon steel (Si-Fe). The lightlysaturated point of the material is $1.25 \mathrm{~T}$. High utilization of the stator core is achieved by driving the machine into the saturating region. The no-load tooth flux density $B_{\text {tooth }}$ is selected at $75 \%$ of the lightly-saturated flux density $B_{\max }$. This allows a $25 \%$ margin for the tooth flux density to increase during transient conditions. The example no-load flux density plot for a 6-pole 18-slot stator is shown in Fig. 4 (b).

\section{Basis for the selection of the stator back-iron width and tooth edge height:}

The stator back-iron passes the flux of each pole-pair through the stator teeth. Half of the stator teeth associated with one pole links through the back-iron and is also observed in Fig. 4 (b). Hence, the required back-iron width is chosen to maintain a flux-density $B_{\text {back-iron }}$ at the same level as the stator teeth, i.e. at $0.75 B_{\max }$.

Approximately $50 \%$ of the flux entering the tooth may transverse through the two tooth edges. The tooth edge height is selected such that tooth edge is non-saturated under no-load conditions. For the comparison of different machine designs, $h_{s 0}$ is selected at the minimum value of $\frac{1}{4} w_{s p}$.

\section{E. Basis for the selection of the stator tooth depth:}

Once the tooth width and back-iron width are calculated, the slot area is determined by the tooth depth. Lower tooth depth will incur lower slot area, lower copper area, and hence higher copper losses. In the turbo-generator design considered in the paper, the stator outer diameter is constrained at 165 $\mathrm{mm}$. Therefore, the tooth depth is selected in order to achieve highest possible slot area when the stator outer diameter is at its upper limit.

Once these preliminary dimensions are selected, an estimate of the machine inductance and PM flux-linkage can be established in order to evaluate the volt-ampere requirements of the machine. The estimation of the machine inductance and PM flux-linkage is presented in the following section.

\section{Modelling OF MACHINE INDUCTANCE AND PM FLUX-LINKAGE}

The operating point of the machine is directly influenced by the parameters $L$ and $\lambda_{p m}$. The relationship between these parameters and the winding geometry is analytically modelled in this section.

\section{A. Estimation of PM flux-linkage:}

The PM flux-linkage is estimated by [18]:

$$
\lambda_{p m}=\frac{N_{s} k_{w, 1} B_{a i r g a p} D_{i s} l_{s t k}}{p}
$$

where $B_{\text {airgap }}$ is the peak air-gap flux density.

\section{B. Estimation of inductance:}

Due to the round rotor construction considered in this study, the d-q inductances are nearly equal $L=L_{d}=L_{q}$ and is estimated as:

$$
L=L_{m}+L_{l}+L_{e w}
$$

where the three terms sequentially represent the magnetizing inductance, leakage inductance and the end-winding inductance.

1) Estimation of magnetizing inductance: The magnetizing inductance $L_{m}$ is estimated via [18], [19]:

$$
L_{m}=\frac{3}{\pi} \mu_{0}\left(\frac{N_{s} k_{w 1}}{p}\right)^{2} \frac{D_{i s} l_{s t k}}{g_{e f}}
$$

The effective air-gap $g_{e f}=k_{g} g$ is adjusted with $k_{g} \geq 1$ for consideration of the slot-opening and saturation effects. The $k_{g}$ value is initially assumed at 1.2 and iteratively adjusted according to the process shown in Fig. 7.

TABLE II

$\chi$ FOR THE DIFFERENT NUMBER OF LAYERS $N_{l y}$, COIL PITCH $\tau_{c}$

\begin{tabular}{l||cccccc}
\hline \hline$N_{l y}$ & 2 & 1 & 2 & 2 & 1 & 2 \\
$\tau_{c}$ & 1 & 3 & 2 & 4 & 5 & 5 \\
\hline$\chi$ & $\frac{1}{2}$ & 1 & $\frac{1}{2}$ & $\frac{5}{6}$ & 1 & $\frac{3}{4}$ \\
\hline
\end{tabular}

2) Estimation of leakage inductance: The total leakage inductance is estimated by [19]:

$$
L_{l}=\mu_{0}\left(2 N_{s}\right)^{2} \frac{m l_{s t k}}{Q} \mathrm{P}_{l}
$$


where the leakage permeance factor $\mathrm{P}_{l}$ can be estimated by the equation [19]:

$$
\begin{aligned}
\mathrm{P}_{l}= & \frac{k_{1}\left(h_{s 2}-h_{s d 1}-h_{s d 2}\right)}{\frac{3}{2}\left(b_{s 2}+b_{s 1}\right)}+\left(\frac{h_{s d 1}}{4 b_{s 1}}+\frac{h_{s d 2}}{4 b_{s 2}}\right) \\
& +k_{2}\left\{\frac{h_{s 0}}{b_{s 0}}+\frac{h_{s 1}}{b_{s 1}-b_{s 0}} \ln \left(\frac{b_{s 1}}{b_{s 0}}\right)\right\}+k_{1}\left(\frac{5 g}{5 b_{s 0}+4 g}\right)
\end{aligned}
$$

where $k_{1}=\frac{5+3 \chi}{8}$ and $k_{2}=\frac{1+\chi}{2}$. The parameter $\chi$ represents the effect of having different phases in a double layer winding coil-sides. For a single layer winding $\chi=1$ [19]. For short pitched double layer windings, $\chi$ is calculated by: $\chi=\frac{1}{2 q} \sum_{n=1}^{2 q} \kappa_{n}$ where $\kappa_{n}=1$ for slots with coil-sides of the same phase and $\kappa_{n}=0.5$ for slots with coil-sides of different phases [19] over $n$ number of coil-sides per-pole perphase. The values of $\chi$ for the different slot/pole combinations considered in this study are also shown in Table II.

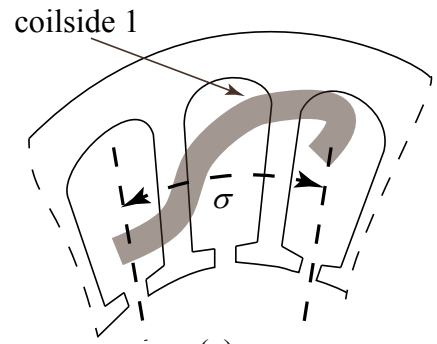

(a)

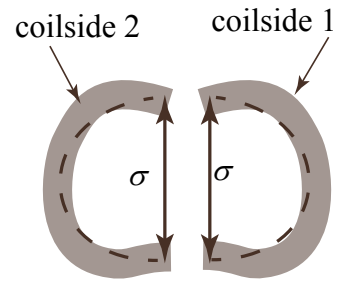

(b)
Fig. 5. (a) End winding typical geometry and (b) flattened end winding

3) Estimation of end-winding inductance: Due to the short stack length associated with the machine, the end winding inductance is a significant proportion of the overall inductance. In order to design the machine to operate in field weakening mode, the end winding inductance needs to be considered. As shown in Fig. 5 (a), a single coil-side of an end winding effectively occupies a coil pitch and when flattened can be approximated to a half-circle of diameter $\sigma$ [20] as shown in Fig. 5 (b). The end winding inductance per coil can be considered as full circle of conductors and can be approximated to [20]:

$$
L_{e w, \text { coil }}=\frac{\mu_{0} \sigma N_{c}^{2}}{2} \ln \left\{\frac{4 \sigma}{0.447 \sqrt{A_{\text {cond }} N_{c}}}-2\right\}
$$

where $N_{c}=\frac{N_{s}}{\left(\frac{Q N_{l y}}{2 m}\right)}$ and $\sigma=\frac{2 \pi \tau_{c}}{Q}\left(\frac{D_{i s}}{2}+h_{s 0}+h_{s 1}+\frac{h_{s 2}}{2}\right)$

The total end winding inductance per-phase is then given by:

$$
L_{e w}=\frac{Q N_{l y}}{2 m} L_{e w, c o i l}
$$

The equations (1) (2), (3), (4) and (6) establish the relationship between $\left(\lambda_{p m}, L\right)$ and $\left(N_{s}, l_{s t k}\right)$ combinations. This is then utilized in Sec. $\mathrm{V}$ to refine a large number of machine design over a range of $N_{s}$ and $l_{s t k}$ values when remaining cross sectional dimensions are fixed. The following section derives inductance limitations that can then be translated to physical $\left(N_{s}, l_{s t k}\right)$ limitations to fulfill the specified torque speed characteristics.

\section{INDUCTANCE REQUIREMENT FOR FIELD WEAKENING AND, CURRENT AND VOLTAGE LIMITATIONS}

The standard PM Machine d-q model is given by [18]:

$$
\begin{aligned}
& v_{q}=R i_{q}+L_{q} \frac{d i_{q}}{d t}+\omega_{e} L_{d} i_{d}+\omega_{e} \lambda_{p m} \\
& v_{d}=R i_{d}+L_{d} \frac{d i_{d}}{d t}-\omega_{e} L_{q} i_{q} \\
& T=\frac{3}{2} \frac{p}{2}\left\{\lambda_{p m} i_{q}+\left(L_{d}-L_{q}\right) i_{d} i_{q}\right\}
\end{aligned}
$$

Considering $L=L_{d}=L_{q}$, the above model is used for the evaluation of the operational feasibility of a given machine design below the base speed and above the base speed.

\section{A. Operation below the base-speed:}

During operation below base-speed $\omega_{b}$ (speed at which the DC-link voltage limit is reached), field weakening is not imposed and hence $i_{d}=0$. The steady-state $\mathrm{d}$-q axis voltage can be approximately written by neglecting the resistance and derivative terms as:

$$
\begin{aligned}
& v_{q}=\omega_{e} \lambda_{p m} \\
& v_{d}=-\omega_{e} L_{q} i_{q, \max }
\end{aligned}
$$

The peak terminal voltage $v_{t}$ can be written as:

$$
v_{t}^{2}=\left(\omega_{e} \lambda_{p m}\right)^{2}+\left(\omega_{e} L_{q} i_{q, \max }\right)^{2}
$$

At the base speed, the electrical speed $\omega_{e}=\frac{p}{2} \omega_{b}$, the following condition must be satisfied:

$$
\left(\omega_{e} \lambda_{p m}\right)^{2}+\left(\omega_{e} L_{q} i_{q, \max }\right)^{2} \leq v_{\max }^{2}
$$

where $i_{q, \max }$ is the current required to produce the maximum torque requirement in motoring mode. The turbo-generator generating torque is lower than the motoring torque requirement and hence the $i_{q, \max }$ correspond to the motoring mode maximum. For a given PM flux-linkage $\lambda_{p m}$, this is given by:

$$
i_{q, \max }=\frac{4 T_{\max }}{3 p \lambda_{p m}}
$$

Substitution of (15) in (14) yields:

$$
\left(\omega_{e} \lambda_{p m}\right)^{2}+\left(\omega_{e} L \frac{4 T_{\max }}{3 p \lambda_{p m}}\right)^{2} \leq v_{\max }^{2}
$$

For a given PM flux-linkage, the inductance limitation is of the form: $L \leq L_{\max }$ where $L_{\max }$ is given by:

$$
L_{\max }=\left(\frac{3 p \lambda_{p m}}{4 T_{\max } \omega_{e}}\right) \sqrt{\left(v_{\max }^{2}-\left(\omega_{e} \lambda_{p m}\right)^{2}\right)}
$$

$L_{\max }$ is the maximum inductance to achieve the required maximum torque without field weakening at a given electrical speed $\omega_{e}$. 


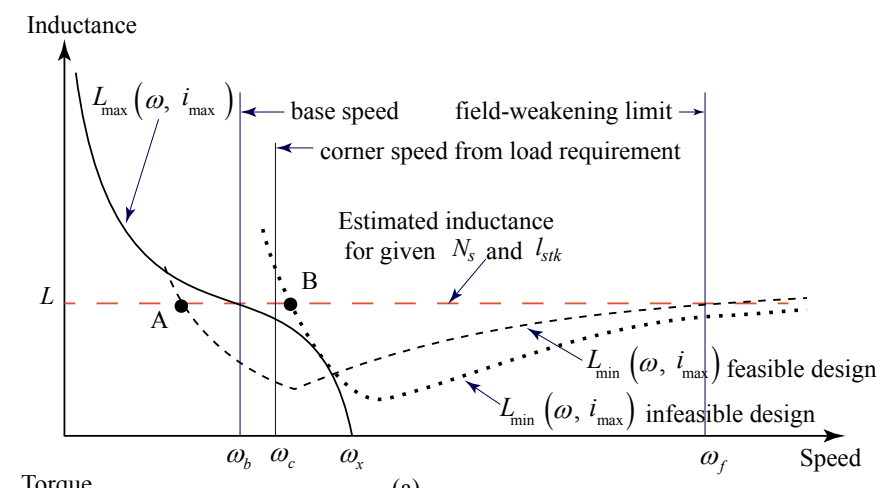

Torque

Magnitude

(a)

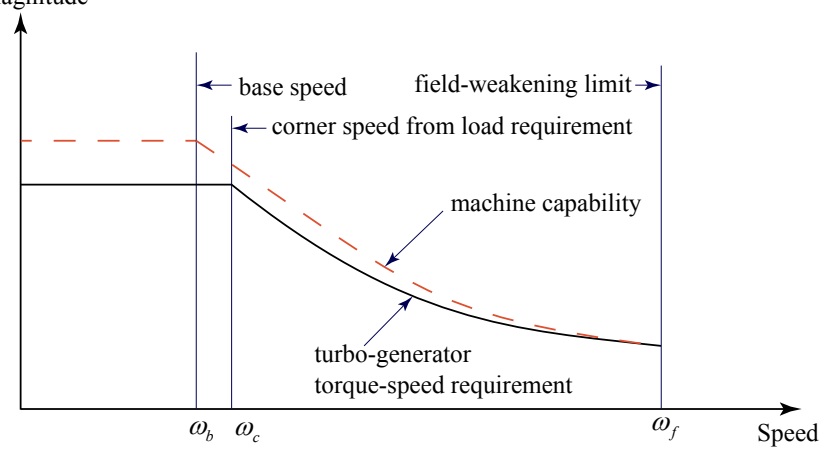

(b)

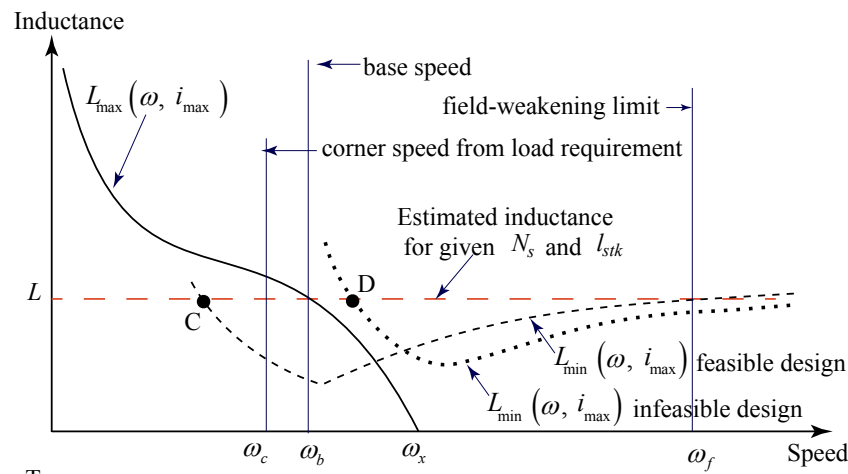

Torque

Magnitude

个 (c)

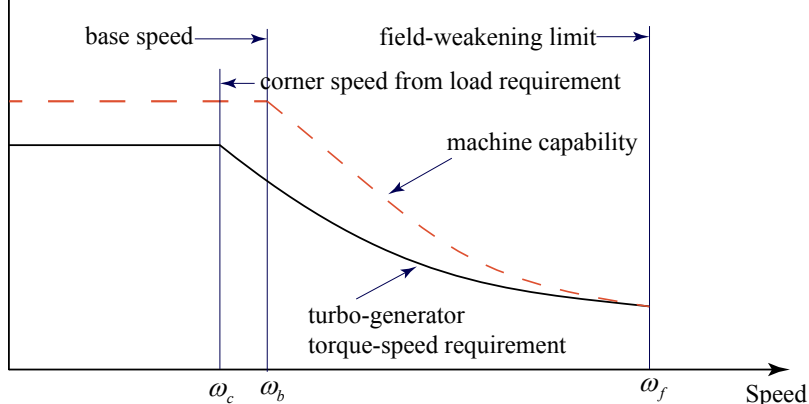

(d)

Fig. 6. Inductance limits vs. speed plot and corresponding torque vs. speed plots: (a) Inductance-speed plot for a feasible machine design and (b) corresponding torque-speed plot, and (c) Inductance-speed plot for an unfeasible machine design and (d) corresponding torque-speed plot.

\section{B. Operation above the base-speed:}

Operation above the base speed is performed in fieldweakening mode. The d-axis current injected to satisfy the condition:

$$
v_{q}^{2}+v_{d}^{2}=v_{\max }^{2}
$$

Neglecting the resistance and derivative terms of (8) and (9) and substitution in (18) yields the steady-state condition:

$$
\left(\omega_{e} L_{d} i_{d}+\omega_{e} \lambda_{p m}\right)^{2}+\left(\omega_{e} L_{q} i_{q}\right)^{2}=v_{\max }^{2}
$$

The d-axis current demand for field-weakening is given by:

$$
i_{d}=\frac{-\omega_{e} \lambda_{p m}+\sqrt{v_{\max }^{2}-\left(\omega_{e} L_{q} i_{q}\right)^{2}}}{\omega_{e} L_{d}}
$$

The field-weakening mode current peak is limited to $i_{\max }$ under steady state operation by the condition:

$$
i_{q}^{2}+i_{d}^{2} \leq i_{\max }^{2}
$$

Substitution of (20) in (21) yields:

$$
\left(\frac{-\omega_{e} \lambda_{p m}+\sqrt{v_{\max }^{2}-\left(\omega_{e} L_{q} i_{q}\right)^{2}}}{\omega_{e} L_{d}}\right)^{2}+i_{q}^{2} \leq i_{\max }^{2}
$$

Expanding the terms within the brackets and rearrangement of terms yield:

$$
\begin{aligned}
\left(\omega_{e} \lambda_{p m}\right)^{2} & +v_{\max ^{2}} \\
& -2 \omega_{e} \lambda_{p m} v_{\max } \sqrt{1-\left(\frac{\omega_{e} L i_{q}}{v_{\max }}\right)^{2}} \leq\left(\omega_{e} L i_{\max }\right)^{2}
\end{aligned}
$$

where $\eta$ is the power conversion efficiency. The quadrature axis current $i_{q}$ at maximum power $P_{\max }$ is given by:

$$
i_{q}=\frac{2 P_{\max }}{3 \eta \omega_{e} \lambda_{p m}}
$$

Substitution of (27) in (25) yields an inequality of the form: 
$L \geq L_{\min }\left(\omega, i_{\max }\right)$ where

$$
L_{\min }=\frac{1}{\omega_{e}} \sqrt{\frac{v_{\max }\left(\omega_{e} \lambda_{p m}\right)^{2}+v_{\max }^{3}-2 \alpha \omega_{e} \lambda_{p m} v_{\max }^{2}}{\left(v_{\max }\left(i_{\max }\right)^{2}-\omega_{e} \lambda_{p m}\left(\frac{2 P_{\max }}{3 \eta \omega_{e} \lambda_{p m}}\right)^{2}\right)}}
$$

\section{Inductance requirement versus speed plot}

The two functions derived as $L_{\max }$ and $L_{\min }$ represent inductance limits that characterize the operational feasibility of a machine for a given machine inductance $L$ and PM fluxlinkage $\lambda_{p m}$. Fig. 6 (a), (b) and (c), (d) represent the two scenarios that could occur.

Fig. 6 (a) shows this scenario, where the machine is required to produce a maximum fixed torque between the speeds $\omega_{b} \leq$ $\omega \leq \omega_{c}$ in field weakening mode prior transit into constant power region. The corresponding torque-speed profile of the machine and turbo-generator requirement are shown in Fig. 6 (b).

Fig. 6 (c) shows this scenario, where the constant power delivery by the turbo-generator can be achieved in the non-field weakening mode. The corresponding torque-speed profile of the machine and turbo-generator are shown in Fig. $6(d)$.

\section{The following key points are highlighted:}

1. The inductance of the machine $L$ has to be lower than the function $L_{\max }$ at a given speed for the machine to operate without field weakening. The speed at the point at which $L_{\max }$ intersects with the inductance line represents the base-speed. 2. The function $L_{\min }$ represent the inductance requirement to achieve field weakening at a given speed. Hence, the inductance $L$ has to be greater than the $L_{\min }$ curve for the machine to operate in field weakening mode.

3. A machine design is rendered an unfeasible solution if the intersection between $L$ and $L_{\min }$ occur above the $L_{\max }$ curve, as shown by points B and D in Fig. 6 (a) and (c) respectively. The machines fail to produce the required turbo-generator torque within the given volt-ampere constraints in the speed interval between the intersection of $L$ with the $L_{\max }$ curve and the $L_{\text {min }}$ curve. In contrast, a machine design can be deemed to be a potential candidate, if the intersection between $L$ and $L_{\text {min }}$ occur below the $L_{\max }$ curve, as shown by points A and $\mathrm{C}$ in Fig. 6 (a) and (c) respectively.

4. The torque-speed requirement exceeds the machine capability curve above a certain speed. The upper speed at which these two curves intersect is shown as $\omega_{f}$ in Fig 6 . The machine will not be able to produce the required torque/power above this speed due to both current and voltage limitations. This speed can be calculated by solving (28) at the upper boundary $L=L_{\min }$.

\section{Design Strategy}

The inductance-limits analysis can be incorporated into a design procedure. The design flow adopted in this research is outlined in Fig. 7 and consists of two parts. Part- 1 consists of deriving a base machine design with unit stack length and

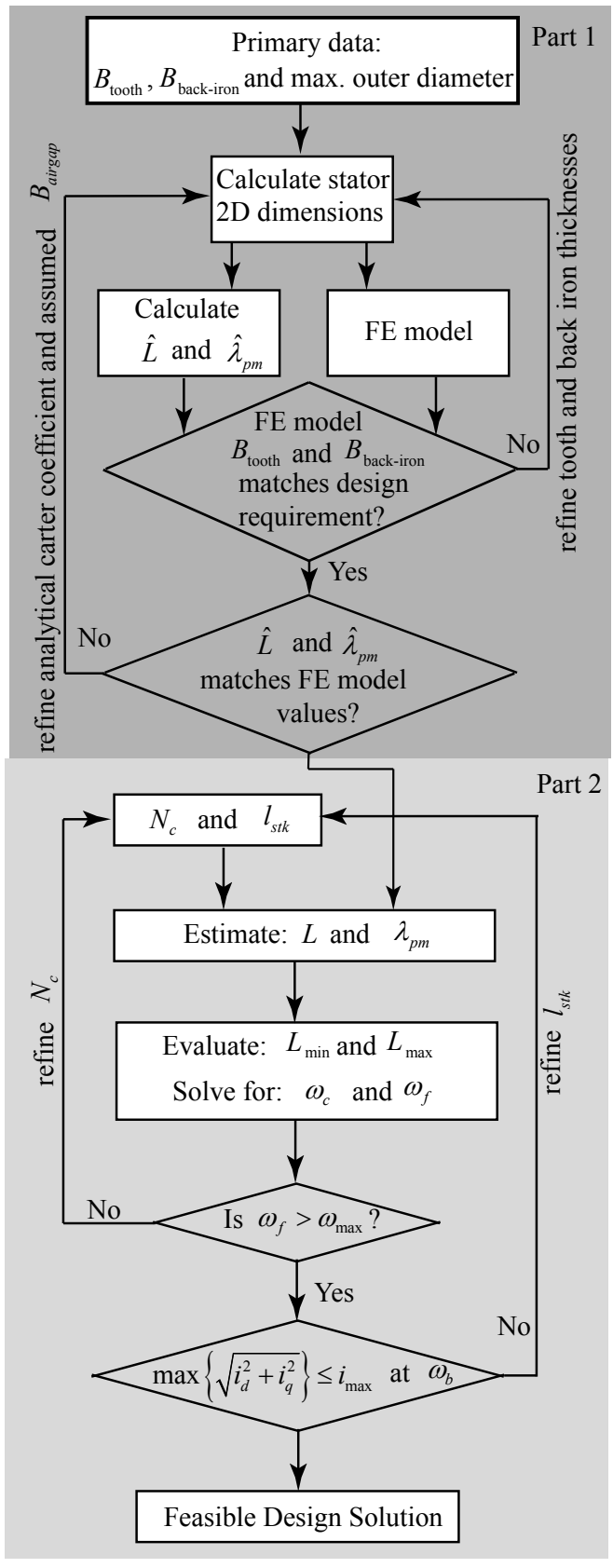

Fig. 7. Design flow diagram

one turn per-slot per-layer $\left(N_{c}=1\right)$. For a given no-load flux density requirement and a maximum outer diameter limit $O D_{\max }$, the stator physical dimensions are calculated using the mathematical background presented in Sec. II. The base machine electrical parameters of inductance $\hat{L}$ and PM fluxlinkage $\hat{\lambda}_{p m}$ are estimated with the mathematical modelling in Sec. III. The air-gap length fixed at $1 \mathrm{~mm}$ for all the designs and not considered as variable. It should be noted that the $(\hat{.})$ notation is used here to represent the base machine electrical parameters. The base machine designs are also implemented in FE software both in 2D and 3D. The end winding effects of the base machines are extracted from the difference between the $2 \mathrm{D}$ and $3 \mathrm{D}$ FE results. The mismatch between FE based results and the estimated end winding inductance is corrected 
by adjustment of the effective diameter of the flattened portion $\sigma$ in the analytical calculation (6). The mismatch between FE based results and analytical calculated PM flux-linkage, magnetizing inductance and the leakage inductance are corrected by refinement of the carter coefficient in (3). Using the base machine parameters, the inductance and PM flux-linkage for a given number of turns per-slot per-layer and stack length are calculated by:

$$
\begin{aligned}
& L=N_{c}^{2} l_{s t k} \hat{L}_{m}+N_{c}^{2} l_{s t k} \hat{L}_{l}++N_{c}^{2} \hat{L}_{e w} \\
& \lambda_{p m}=N_{c} l_{s t k} \hat{\lambda}_{p m}
\end{aligned}
$$

In Part-2, the value for the number of turns per-slot perlayer and stack length are chosen and the machine feasibility is established by evaluation of the $L_{\max }$ and $L_{\min }$ characteristics as explained in the previous section. If the feasible maximum speed is below the required maximum speed from specifications, the number of turns per-slot per-layer is refined. Thereafter the maximum current requirement (typically at the operating point at the corner speed $\omega_{c}$ ) is evaluated. If the required maximum torque cannot be produced at this speed, the stack length is increased and the evaluation of feasibility is repeated.

This strategy rapidly produces machine solutions that are feasible, otherwise which may have required intensive FE simulation and analysis. Detailed FE simulations are performed only on this set of feasible machine designs and the final machine is selected based on efficiency and weight considerations.

\section{Simulation AND EXPERIMENTAL RESUlts}

\section{A. Simulation study on feasible designs:}

The efficiency at the maximum speed operating point and weight are evaluated with FE simulations for a number of feasible machine designs and are summarized in the Fig. 8 scatter plot. The color of the scatter plot represents the copper losses at 360 A current, $55 \mathrm{Nm}$ torque production at the $\omega_{c}$ operating point. It can be clearly seen that the 4-pole machine options are of low efficiency. The designs A1, A2 and A3 are not shown in Fig. 8 due to efficiency below $90 \%$. The 8-pole designs achieve the highest efficiency and comparatively lower weight.

The 8-pole machines such as C12, C8 and C7 stand out with high efficiency as well as comparative low weight machines and has copper losses in the neighborhood of $3.2 \mathrm{~kW}$ to 3.5 $\mathrm{kW}$ at the $55 \mathrm{Nm} / 8000 \mathrm{rpm}$ starter operating point. The group of 8-pole machines C3, C4 C5, C9, C10 achieve high efficiencies at the cost of higher weight in comparison with the 6-pole counterpart. These machines also achieve copper losses less than $2.3 \mathrm{~kW}$ at the starter operating point. The C10 machine can be considered as the most optimal machine design that achieves the best efficiency with an optimal tradeoff of weight and with the lowest copper loss of $2 \mathrm{~kW}$ at the starter operating point.

The 6-pole machines B6, B10, B16 and B17 in the low weight range incur copper losses in excess of $5 \mathrm{~kW}$ at starter operating point and is found to be thermally challenging designs. Machines with intermediate weights and intermediate
TABLE III

MACHINE SOLUTIONS REPRESENTED BY XX WITH DIFFERENT POLE NUMBER $(p)$, SLOT NUMBER $(Q)$, STACK LENGTH $\left(l_{s t k}\right)$ AND NUMBER OF

\begin{tabular}{|c|c|c|c|c|c|c|c|}
\hline XX & $p / Q$ & $\begin{array}{c}l_{s t k} \\
{[\mathrm{~mm}]}\end{array}$ & $N_{c}$ & XX & $p / Q$ & $\begin{array}{c}l_{s t k} \\
{[\mathrm{~mm}]}\end{array}$ & $N_{c}$ \\
\hline A1 & $4 / 6$ & 84.5 & 26 & $\overline{\text { B10 }}$ & $6 / 27$ & 57.2 & 7 \\
\hline A2 & $4 / 6$ & 92.5 & 22 & B11 & $6 / 27$ & 65.7 & 6 \\
\hline A3 & $4 / 12$ & 69.5 & 12 & B12 & $6 / 27$ & 78.9 & 5 \\
\hline A4 & $4 / 12$ & 83.4 & 10 & B13 & $6 / 36$ & 59.6 & 5 \\
\hline A5 & $4 / 12$ & 70.5 & 14 & B14 & $6 / 36$ & 72 & 4 \\
\hline A6 & $4 / 12$ & 82.2 & 12 & B15 & $6 / 36$ & 95.9 & 3 \\
\hline A7 & $4 / 18$ & 65.4 & 9 & B16 & $6 / 36$ & 52 & 6 \\
\hline A8 & $4 / 18$ & 84.1 & 7 & B17 & $6 / 36$ & 59.6 & 5 \\
\hline A9 & $4 / 24$ & 61.2 & 7 & B18 & $6 / 36$ & 74.5 & 4 \\
\hline A10 & $4 / 24$ & 85.7 & 5 & B19 & $6 / 36$ & 99.3 & 3 \\
\hline A11 & $4 / 24$ & 74.6 & 6 & C1 & $8 / 12$ & 88.5 & 12 \\
\hline A12 & $4 / 24$ & 89.5 & 5 & $\mathrm{C2}$ & $8 / 12$ & 88 & 13 \\
\hline B1 & $6 / 9$ & 81.1 & 18 & C3 & $8 / 24$ & 87.5 & 5 \\
\hline B2 & $6 / 18$ & 63.9 & 9 & $\mathrm{C} 4$ & $8 / 24$ & 74.8 & 6 \\
\hline B3 & $6 / 18$ & 69.5 & 8 & C5 & $8 / 24$ & 86.4 & 6 \\
\hline B4 & $6 / 18$ & 79.5 & 7 & C6 & $8 / 24$ & 74 & 7 \\
\hline B5 & $6 / 18$ & 92.5 & 6 & C7 & $8 / 24$ & 67.5 & 8 \\
\hline B6 & $6 / 18$ & 60.8 & 11 & C8 & $8 / 36$ & 63.2 & 5 \\
\hline B7 & $6 / 18$ & 66.9 & 10 & C9 & $8 / 36$ & 77.5 & 4 \\
\hline B8 & $6 / 18$ & 74.3 & 9 & $\mathrm{C} 10$ & $8 / 48$ & 72.5 & 3 \\
\hline \multirow[t]{2}{*}{ B9 } & $6 / 18$ & 83.5 & 8 & C11 & $8 / 48$ & 78.5 & 3 \\
\hline & & & & C12 & $8 / 48$ & 58.9 & 4 \\
\hline
\end{tabular}
CONDUCTORS PER SLOT $\left(N_{c}\right)$

XX - Double layer winding

XX - Single layer winding

TABLE IV

LOSSES OF DIFFERENT DESIGNS AT THE 8000 RPM FULL-LOAD OPERATING POINT AND 32000 RPM FULL-LOAD OPERATING POINT

\begin{tabular}{l|ccc|ccc}
\hline & \multicolumn{2}{|c|}{ at 8000 rpm } & \multicolumn{2}{c}{ at 32000 rpm } & \\
\hline XX & $\begin{array}{c}\text { copper } \\
\text { losses } \\
{[\mathrm{W}]}\end{array}$ & $\begin{array}{c}\text { core } \\
\text { losses } \\
{[\mathrm{W}]}\end{array}$ & $\begin{array}{c}\text { magnet } \\
\text { losses } \\
{[\mathrm{W}]}\end{array}$ & $\begin{array}{c}\text { copper } \\
\text { losses } \\
{[\mathrm{W}]}\end{array}$ & $\begin{array}{c}\text { core } \\
\text { losses } \\
{[\mathrm{W}]}\end{array}$ & $\begin{array}{c}\text { magnet } \\
\text { losses } \\
{[\mathrm{W}]}\end{array}$ \\
\hline C7 & 3567 & 92 & 7.7 & 1192 & 89 & 24 \\
C8 & 3283 & 93 & 3.6 & 1088 & 96 & 17 \\
C12 & 3516 & 90 & 1.4 & 1153 & 87 & 6 \\
B3 & 3111 & 76 & 22.4 & 1065 & 82 & 76 \\
B8 & 3579 & 83 & 22.2 & 1338 & 92 & 84 \\
B9 & 3019 & 86 & 20.3 & 1302 & 103 & 84 \\
B12 & 3529 & 74 & 6.6 & 1606 & 93 & 40 \\
B14 & 3148 & 75 & 2.6 & 1197 & 95 & 22 \\
B18 & 3505 & 75 & 0.8 & 1651 & 88 & 16 \\
\hline
\end{tabular}

copper loss at the starter operating point such as B3, B8, B9, B12, B14 and B18 are found to be the cohort of machines with balanced trade-off of weight and efficiency. Further simulation results are of the best 8-pole machines cohort and the 6-pole machines cohort are presented in the following section.

The cohort of 8-pole machines $\mathrm{C} 7, \mathrm{C} 8$ and $\mathrm{C} 12$, and 6-pole machines B3, B8, B9, B12, B14 and B18 are further evaluated. Table IV presents the breakdown of individual losses of the machines at $8000 \mathrm{rpm}$ and $32000 \mathrm{rpm}$ operating points. All the machines are shown to achieve considerably low core-losses due to the use of low-loss super-core $6.5 \% \mathrm{Si}$ steel. The eddy current losses impact the heating of the magnets and high eddy current losses pose a demagnetization risk. Hence, the eddy current losses are prioritized for the selection of the final machine design and the machine design $\mathrm{C} 12$ and B18 can be 


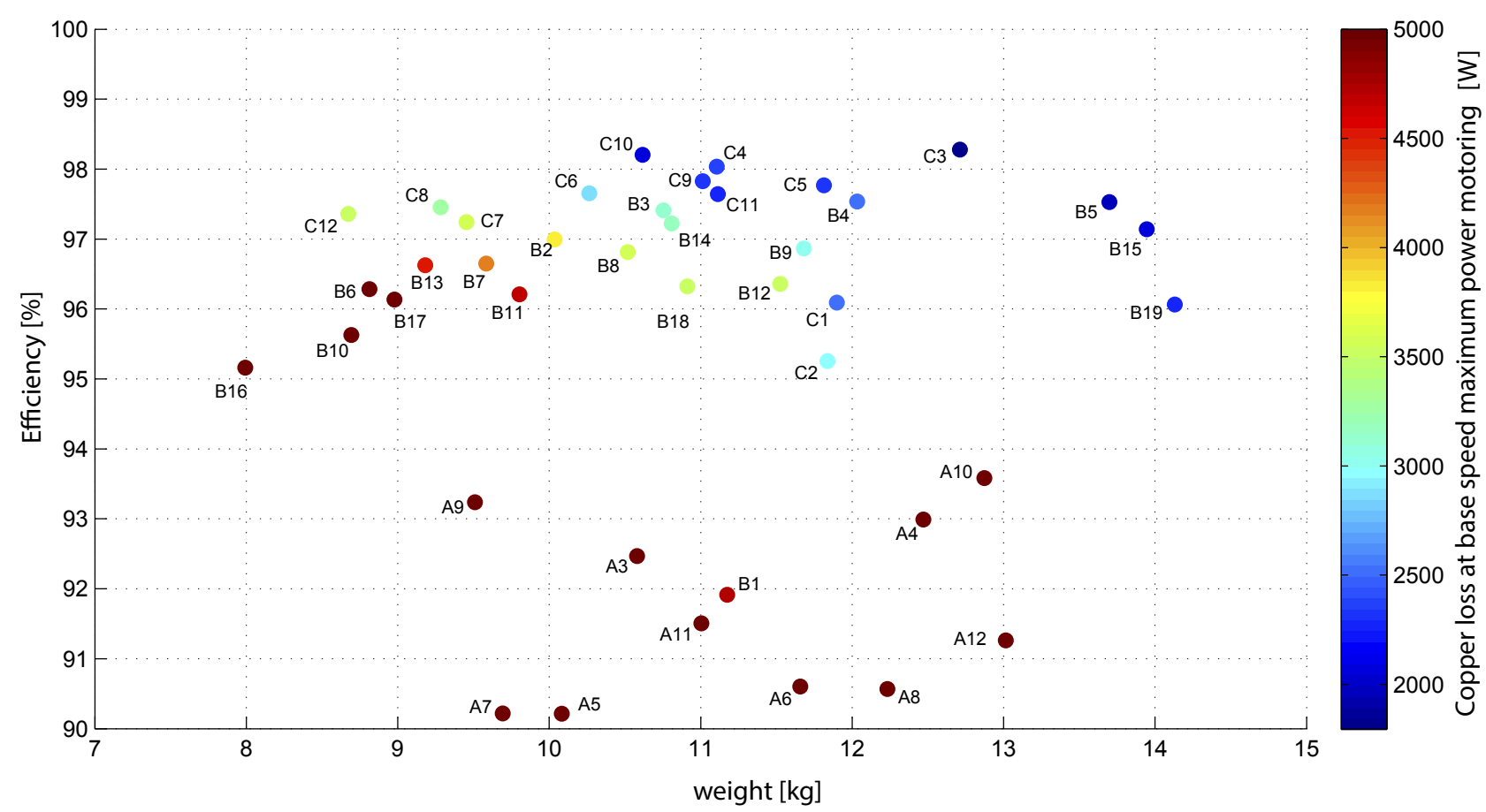

Fig. 8. Summary of machine solutions scatter plot of weight vs. efficiency (at maximum speed) for different machine designs given in Table 1. Colour of point represent the copper loss at full load operation at corner speed.

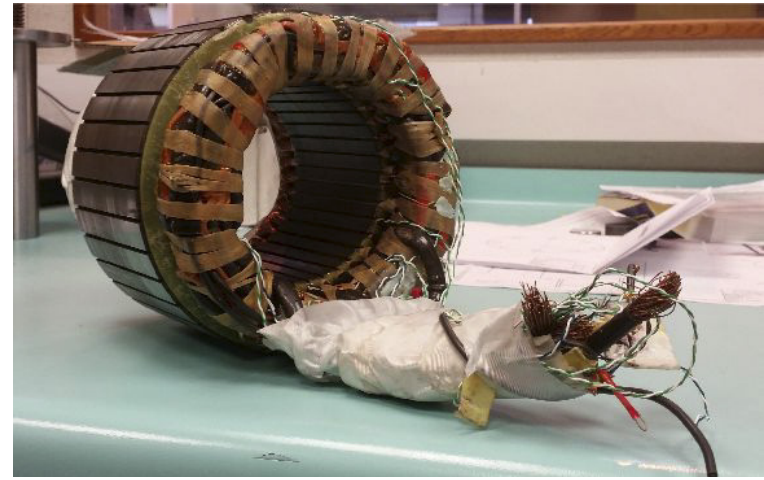

Fig. 9. The fabricated prototype stator

considered as the two designs that have the lowest eddy current losses. The rated power frequency of the 8-pole machines are at $2.13 \mathrm{kHz}$ and the 6-pole are at $1.6 \mathrm{kHz}$. Due to the need for power electronic switching frequencies, only the 6-pole machine option B18 has been considered for fabrication.

\section{B. Experimental results of the prototype}

TABLE V

KEY DESIGN PARAMETERS OF FINAL PROTOTYPE STATOR

Structure and winding: $Q=36, p=6, m=3, q=2, N_{l y}=2$ $N_{c}=4, N_{s}=24, \tau_{c}=5, k_{w, 1}=0.933, l_{s t k}=74.5 \mathrm{~mm}$

Tooth dimensions: , $b_{s 0}=4 \mathrm{~mm}, h_{s 0}=1.1 \mathrm{~mm}$

$h_{s 1}=1 \mathrm{~mm}, h_{s 2}=19.6 \mathrm{~mm}, h_{s 3}=12.9 \mathrm{~mm}$

Fixed dimensions: $D_{i s}=96 \mathrm{~mm},, g=1 \mathrm{~mm}, h_{p m}=10 \mathrm{~mm}$

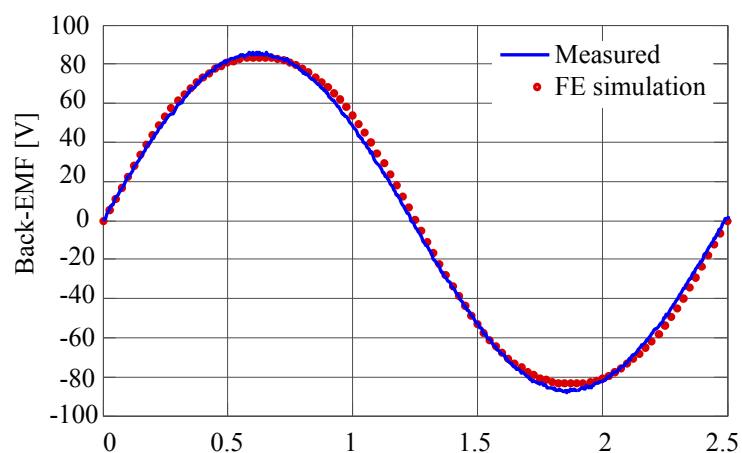

(a) Time $[\mathrm{ms}]$

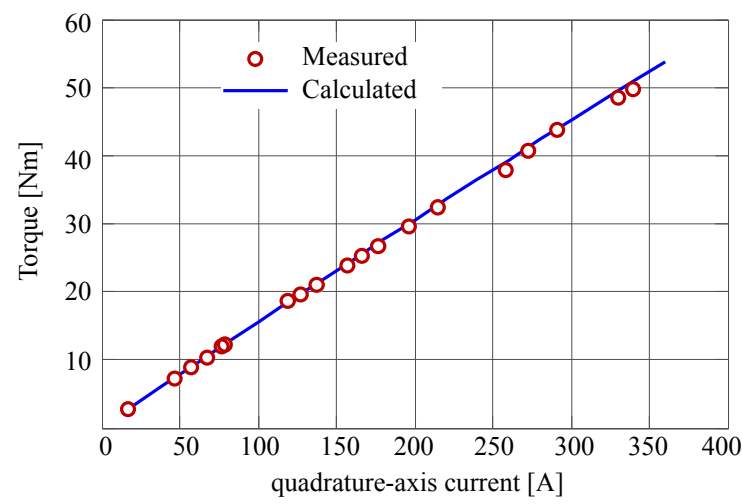

(b) Time $[\mathrm{ms}]$

Fig. 10. Experimental results: (a) Back-EMF waveform at $8000 \mathrm{rpm}$ and (b) Torque production with Q-axis current

Fig. 9 shows the prototype stator of the B18 machine 
designed with the prototype rotor shown in Fig. 1 (a). The detailed key design parameters if the prototype is outlined in Table V. The back-EMF waveform at $8000 \mathrm{rpm}$ has been obtained and is compared with the simulation results in Fig. 10 (a). In addition, the torque production at $8000 \mathrm{rpm}$ at different quadrature axis currents is obtained and is compared with the simulation results in Fig. 10 (b). Both these experimental tests match the simulation results accurately.

TABLE VI

COMPARISON BETWEEN PREDICTED AND MEASURED MACHINE PARAMETERS

\begin{tabular}{l|ll}
\hline Parameter & Predicted & Measured \\
\hline Resistance & $16.10 \mathrm{~m} \Omega$ & $15.43 \mathrm{~m} \Omega$ \\
Inductance $L_{d}$ & $101 \mu \mathrm{H}$ & $98 \mu \mathrm{H}$ \\
Inductance $L_{q}$ & $100.5 \mu \mathrm{H}$ & $102 \mu \mathrm{H}$ \\
\hline
\end{tabular}

The inductance and the resistance of the winding have been measured. From the comparison given in Table VI, it can clearly be seen that the results are in good agreement and error between measured and FE predicted values are less than $5 \%$.

TABLE VII

COMPARISON BETWEEN PREDICTED AND MEASURED LOSSES AND EFFICIENCY FOR DIFFERENT OPERATING POINTS

\begin{tabular}{|c|c|c|c|c|c|}
\hline $\begin{array}{l}\text { Speed } \\
{[\mathrm{rpm}]}\end{array}$ & $\begin{array}{l}\text { Winding } \\
\text { Temp. }\end{array}$ & & $\begin{array}{l}\text { Torque } \\
\text { [Nm] }\end{array}$ & $\begin{array}{l}\text { Total losses } \\
{[\mathrm{W}]}\end{array}$ & $\begin{array}{l}\text { Efficiency } \\
{[\%]}\end{array}$ \\
\hline \multirow{2}{*}{9000} & \multirow{2}{*}{$114^{0} \mathrm{C}$} & predicted & 41.94 & 2646 & 93.3 \\
\hline & & measured & 40.57 & 2491 & 93.8 \\
\hline \multirow{2}{*}{20025} & \multirow{2}{*}{$101{ }^{0} \mathrm{C}$} & predicted & 21.69 & 3224 & 92.9 \\
\hline & & measured & 20.72 & 3263 & 92.4 \\
\hline
\end{tabular}

Table VII shows the measured losses and efficiency in comparison with FE predicted results in the neighborhood of $40 \mathrm{~kW}$ loading. The operation at $9000 \mathrm{rpm}$ is near the base speed and $20025 \mathrm{rpm}$ is in field weakening mode. In the $20025 \mathrm{rpm}$ operating point, the machine was able to deliver $95.5 \%$ of the power predicted by calculations and therefore is in good agreement and thereby validates field weakening mode operation. From Table VII, it is evident that the machine provides the expected high efficiency of more than $93 \%$ at the $40 \mathrm{~kW}$ loading condition. Due to drive system speed limitations, it was not possible to drive the machine up to its maximum speed of $32000 \mathrm{rpm}$. However, these results validate the stator design and confirm that the adopted procedure achieves results very close to that expected at designs stage..

\section{CONCLUSION}

A strategy to design the stator of a high-speed PM machine with a fixed rotor radius has been presented in this paper. The developed strategy links volt-ampere limitations to stator design parameters such as stack-length, slot/pole combination and winding arrangement. This has been achieved by means of analysis of the PM flux linkage and inductance requirement to achieve field weakening operation for given torque/speed specifications. The concept of inductance-limits analysis has been presented in mathematical detail that will be useful for machine designers to establish the feasibility of preliminary stator designs.
The procedure adopted to design a candidate stator for a turbo-generator application has been presented. The design involves selection of preliminary physical dimensions of the stator of a base machine with unit stack length and unit number of winding turns per-slot-per-layer. The PM flux-linkage and inductance values of the base machines have been calculated with analytical modelling, and corrected for end winding and leakage effects using a low number of FE simulations. Thereafter, a confined set of feasible stator designs are extracted using inductance-limits analysis. These feasible stator designs have been then further evaluated for efficiency, weight, copperloss at starter operation and magnet eddy current losses at the operating point at maximum speed. Based on these results, the most suitable design option has been selected and the basis for this selection has been discussed in detail. The final machine selection has been prototyped and tested. Simulation and experimental results have been compared and are found to be in good agreement.

\section{REFERENCES}

[1] C. Pornet and A. Isikveren, "Conceptual design of hybrid-electric transport aircraft," Progress in Aerospace Sciences, vol. 79, pp. 114 135, 2015.

[2] Y. Jia and K. Rajashekara, "An induction generator-based ac/dc hybrid electric power generation system for more electric aircraft," IEEE Transactions on Industry Applications, vol. 53, pp. 2485-2494, May 2017.

[3] "MIL-STD-704F Aircraft Electric Power Characteristics," "US Department of Defense", 2004.

[4] A. Damiano, A. Floris, G. Fois, M. Porru, and A. Serpi, "Modelling and design of pm retention sleeves for high-speed pm synchronous machines," in 2016 6th International Electric Drives Production Conference (EDPC), pp. 118-125, Nov 2016.

[5] W. Fernando and C. Gerada, "High speed permanent magnet machine design with minimized stack-length under electromagnetic and mechanical constraints," International Journal of Applied Electromagnetics and Mechanics, vol. 46, no. 1, pp. 95-109, 2014.

[6] W. U. N. Fernando, P. Arumugam, and C. Gerada, "Volt-ampere constrains and its influence on inductance limits in high speed pm machine design," in 8th IET International Conference on Power Electronics, Machines and Drives (PEMD 2016), pp. 1-6, April 2016.

[7] B. Sneyers, D. W. Novotny, and T. A. Lipo, "Field weakening in buried permanent magnet ac motor drives," IEEE Transactions on Industry Applications, vol. IA-21, pp. 398-407, March 1985.

[8] S. Morimoto, Y. Takeda, T. Hirasa, and K. Taniguchi, "Expansion of operating limits for permanent magnet motor by current vector control considering inverter capacity," IEEE Transactions on Industry Applications, vol. 26, pp. 866-871, Sep 1990.

[9] T. M. Jahns, "Flux-weakening regime operation of an interior permanent-magnet synchronous motor drive," IEEE Transactions on Industry Applications, vol. IA-23, pp. 681-689, July 1987.

[10] R. F. Schiferl and T. A. Lipo, "Power capability of salient pole permanent magnet synchronous motors in variable speed drive applications," IEEE Transactions on Industry Applications, vol. 26, pp. 115-123, Jan 1990.

[11] W. L. Soong and T. J. E. Miller, "Field-weakening performance of brushless synchronous ac motor drives," IEE Proceedings - Electric Power Applications, vol. 141, pp. 331-340, Nov 1994.

[12] T. Sebastian and G. R. Slemon, "Operating limits of inverter-driven permanent magnet motor drives," IEEE Transactions on Industry Applications, vol. IA-23, pp. 327-333, March 1987.

[13] D. Ban, D. Zarko, and I. Mandic, "Turbogenerator end-winding leakage inductance calculation using a 3-d analytical approach based on the solution of neumann integrals," IEEE Transactions on Energy Conversion, vol. 20, pp. 98-105, March 2005.

[14] M. F. Hsieh, Y. C. Hsu, D. G. Dorrell, and K. H. Hu, "Investigation on end winding inductance in motor stator windings," IEEE Transactions on Magnetics, vol. 43, pp. 2513-2515, June 2007. 
[15] M. Degano, P. Arumugam, W. Fernando, T. Yang, H. Zhang, J. Bartolo, S. Bozhko, P. Wheeler, and C. Gerada, "An optimized bi-directional, wide speed range electric starter-generator for aerospace application," in Power Electronics, Machines and Drives (PEMD 2014), 7th IET International Conference on, pp. 1-6, April 2014.

[16] M. van der Geest, H. Polinder, J. A. Ferreira, and D. Zeilstra, "Design and testing of a high-speed aerospace permanent magnet starter/generator," in 2015 International Conference on Electrical Systems for Aircraft, Railway, Ship Propulsion and Road Vehicles (ESARS), pp. 1-6, March 2015.

[17] N. Chiodetto, N. Bianchi, and L. Alberti, "Improved analytical estimation of rotor losses in high-speed surface-mounted pm synchronous machines," IEEE Transactions on Industry Applications, vol. 53, pp. 35483556, July 2017.

[18] J. T. M. Bianchi N., Tutorial course notes : Design, analysis, and control of interior pm synchronous machines. Seatle WA: IEEE Industry Applications Society Annual Meeting, 102004.

[19] V. H. Juha Pyrhonen, Tapani Jokinen, Design of Rotating Electrical Machines. Wiley, 2009.

[20] T. Miller, M. McGilp, D. Staton, and J. Bremner, "Calculation of inductance in permanent-magnet dc motors," Electric Power Applications, IEE Proceedings -, vol. 146, pp. 129-137, Mar 1999.

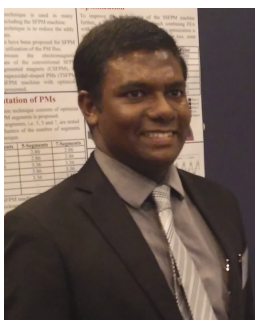

Nuwantha Fernando (M'10) received the B.Sc degree in Electrical Engineering from University of Moratuwa, Sri Lanka in 2008 and the Ph.D degree from the University of Manchester, U.K., in 2012. Subsequently he has been a researcher at the University of Nottingham and thereafter at University of Oxford. He is presently Lecturer at the RMIT University Melbourne. His research interests include electric machines and drives particularly for electric transportation applications. Dr. Fernando serves as an Editor for the IEEE Transactions on Energy

Conversion

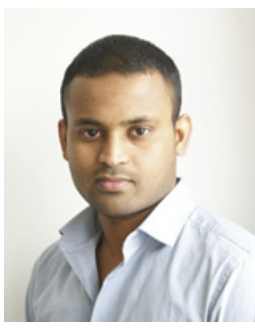

Puvan Arumugam (M'11) received the B.Eng. (Hons.) degree in electrical and electronic engineering from The University of Nottingham, Nottingham, U.K., in 2009, and the Ph.D. degree in electrical machines and drives from The University of Nottingham, Nottingham, U.K., in 2013. $\mathrm{He}$ subsequently worked as a researcher within the Power Electronics, Machines, and Control Group, The University of Nottingham, working on electric aircraft propulsion. He is currently a Senior Project Engineer with the Force Engineering Ltd, Shepshed, UK. His current research interests include electrical machines and drives, electromechanical devices and systems, and analytical computation of electromagnetic fields. Dr. Arumugam was awarded a Hermes Fellowship supported by Technology Transfer Office, The University of Nottingham in 2014.

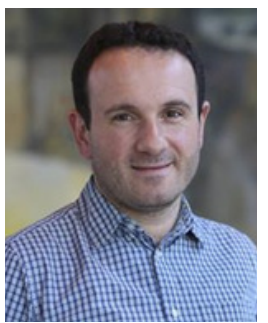

Chris Gerada (M'05) received the Ph.D. degree in numerical modeling of electrical machines from The University of Nottingham, Nottingham, U.K., in 2005. He subsequently worked as a Researcher with The University of Nottingham on high-performance electrical drives and on the design and modeling of electromagnetic actuators for aerospace applications. Since 2006, he has been the Project Manager of the GE Aviation Strategic Partnership. In 2008, he was appointed as a Lecturer in electrical machines; in 2011, as an Associate Professor; and in 2013, as a Professor at The University of Nottingham. His main research interests include the design and modeling of high-performance electric drives and machines. Prof. Gerada serves as an Associate Editor for the IEEE Transactions on Industry Applications and is the Chair of the IEEE IES Electrical Machines Committee. 